\title{
Two Step Homogeneous Catalized Metanolysis of Rubber Seed Oil To Biodiesel
}

\author{
Umeezuegbu J.C. \\ Department of Chemical Engineering, Faculty of Engineering \\ Chukwuemeka Odumegwu Ojukwu University, Anambra State, Nigeria. \\ umejonah@gmail.com
}

\begin{abstract}
The rapid depletion of fossil fuel and its environmental impact has resulted in the search for alternative energy sources. Among the various alternatives investigated for diesel replacement, biodiesel has emerged the most suitable alternative to diesel fuel. This research work is therefore focused on the use of low cost none-edible rubber seed oil, methanol solvent and sodium hydroxide catalyst for production of rubber seed oil (RSO) fatty acid methyl ester (RSOFAME). as a renewable energy. The oil content of rubber seed was extracted using solvent extraction method. The RSO extracted was characterized based on American Society for Testing and Materials (ASTM) methods. The fatty acid profile was determined using gas chromatography mass spectrometry while the functional group of the oil was analyzed using Fourier transform infrared spectroscopy. The effect of process parameter on the yield of RSOFAME was investigated using one factor at a time method. The RSO was pretreated to reduce the free fatty acid below $1 \%$ and then transterified using methanol in the presence of sodium hydroxide $(\mathrm{NaOH})$ catalyst. The fuel properties of the RSOFAME produced was determined based on ASTM standards. The physiochemical properties of RSO, acid value, free fatty acid, saponification value, iodine value, peroxide value, kinematic viscosity, fire point, flash point, cloud point, pour point, refractive index specific gravity, moisture content, and density gave the values $28.72 \mathrm{mgKOHg}-1,14.36 \%$, $185.66 \mathrm{mgKOHg}-1$ 120.4gI2100g-1, $14.62 \mathrm{meqkg}-1,38.5 \mathrm{~mm} 2 \mathrm{~s}-$ $1 @ 400 \mathrm{C}, 1800 \mathrm{C}, 1320 \mathrm{C}, 60 \mathrm{C}, 20 \mathrm{C} 1.428,0.92,7 \%, 920 \mathrm{Kgm}-$ 3 , respectively. The fatty acid profile of RSO shows the constituent unsaturated fatty acids to be oleic acid $19.6 \%$ and linoleic acid $22.588 \%$, while the saturated fatty acid constituents are lauric acid $3.983 \%$, myristic acid $7.750 \%$, palmitic acid $16.698 \%$, stearic acid $39.058 \%$ The process parameters greatly affected the biodiesel yield. The experimentally determined properties of the RSOFAME, density, kinematic viscosity, cetane number,, flash point, cloud point, water content, acid value, calorific value, iodine value, and pour point gave the values, $880 \mathrm{kgm}-34.25 \mathrm{~mm} 2 \mathrm{~s}-1,58.2,1640 \mathrm{C}$, 40C. $0.44 \%$, $0.32 \mathrm{mgKOHg}-1, \quad 38.5 \mathrm{MJkg}-1,72 \mathrm{gI} 2100 \mathrm{~g}-1,20 \mathrm{C}$, respectively.
\end{abstract}

\section{Keywords}

Characterization, methanolysis, rubber seed oil, synthesis, transesterification

\section{INTRODUCTION}

The fossil fuels, petroleum, coal and natural gas, the major energy sources of the world is fast depleting owing to increase in population and high spate of industrial development. It has been reported that 75 million barrels of crude oil is consumed daily worldwide [1]. It is therefore envisaged that a time is coming when the fossil fuel will eventually be exhausted Burning of fossil fuel causes environmental concerns such as greenhouse gas emission, the major substance causing climatic change. Harmful substances released during fossil fuel production and utilization include sulphur oxides (SOx), nitrogen oxides (NOx) and methane [2]. The growing concern due to fast depletion and environmental pollution caused by the conventional fossil fuels has led to the search for environmentally friendly and renewable fuels. Among the various alternatives investigated for diesel replacement, biodiesel has proved to be the foremost to reduce exhaust emission [3]. Although, biodiesel is gaining popularity, more than $95 \%$ of the renewable resources used for its production are edible oils [4], which will in a long term have serious implications on food availability and the cost of biodiesel as it may be more expensive than petro-diesel. Worldwide, biodiesel production is mainly from edible oils such as soybean, sunflower canola oils etc. Utilization of edible oils as feedstock for biodiesel production poses a lot of concerns as this practice competes with food supply leading to high cost of edible vegetable oil, and consequently results in relative increase in biodiesel production cost [5]. Therefore, concerted research efforts are geared towards identifying and evaluating non-edible seed oils as suitable feed stocks. There are vast numbers of nonedible oil plants in nature including, neem (A. indica), jatropha tree (J. curcas), karanja (P.pinnata), tobacco seed (N. tabacum L.), rice bran, mahua (M. indica), rubber plant (H. brasiliensis), castor, linseed, and microalgae. Jatropha curcas oil plants have been widely studied with respect to biodiesel production from non-edible oils [6-9], but the use of most of other non-edible oil plants such as rubber, neem, castor etc have not been intensely studied as Jatropha curcas. This research work therefore focused on the use of relatively low cost materials, none-edible rubber seed oil, homogeneous sodium hydroxide catalyst and methanol solvent to produce biodiesel of reduced cost. The rubber tree (Hevea brasiliensis) is a perennial plantation crop, and it's indigenous to South America. Since its introduction to the orient around 1876, it has been cultivated as an industrial crop. The rubber tree grows in hot, humid climates, native of the tropical rain forests of the Amazon valley, is a tall tree that attain the height of about 20m [10]. Rubber seed oil yield from rubber 
plantations varies from 100 to 150 kilogram per hectare depending on soil fertility and crop density. Rubber seeds are not available all the year round. There are two harvesting seasons in a year. Rubber Seed Oil is a semi-drying substance. The RSO has many possible applications for industrial purposes such as, manufacture of fatty acids, paint, alkyd resin, soap, surface coatings, , production of biodiesel fuel used in compression ignition engines [11]. Rubber seed oil extracted from rubber seed is a promising feedstock for biodiesel production. The rubber seed consist of about $40 \%$ kernel with $20-25 \%$ moisture. Approximately $40-50 \%$ of oil is found in the dried kernel which contributes to 20 million liters of oil yearly [12]. Up till now the rubber seeds has not been considered useful and therefore regarded as waste. The oil consist of high percentage of free fatty acid and is therefore unsuitable for biodiesel production by direct transesterification The oil was rather esterified by pretreatment with acid catalyst and then transesterified with alkali catalyst using methanol solvent.

\section{MATERIALS AND METHOD}

\subsection{Materials}

Rubber seeds, reagents, glassware, equipments including gas chromatography mass spectrometer, (GC-MS), Fourier transform infrared spectroscopy (FTIR), viscometer), viscometer, magnetic hot plate, soxhlet extractor.

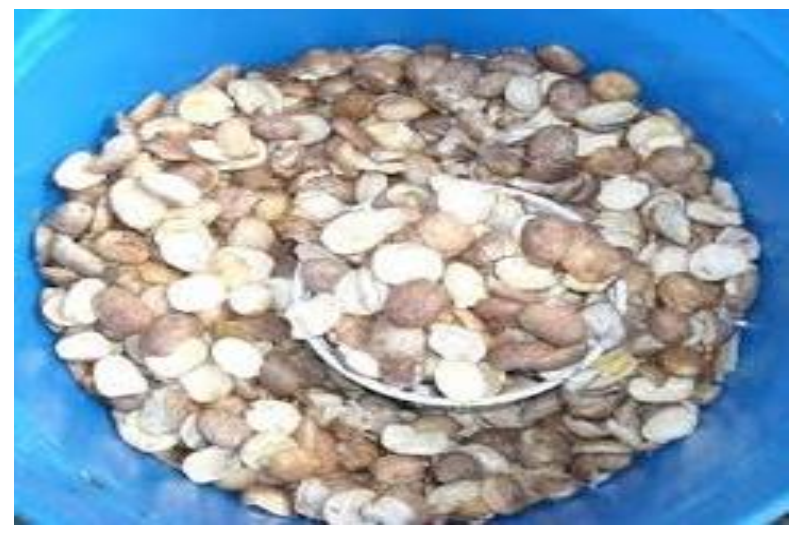

Plate1: Rubber Seeds

\subsection{Experimental Methods}

\subsubsection{Extraction of oil from rubber seeds}

The rubber seeds was purchased from Sapele in Delta state, Nigeria where rubber plantation abound. The seeds were deshelled to remove the kernel from the shell and the inner seed coat was removed by winnowing. The kernel was then dried in an oven at $500 \mathrm{C}$ for five hours to reduce the water content. It was then grind with mechanical grinder in order to expose more surface area of the seed for faster and maximum oil extraction. Solvent extraction using soxhlet extractor was used for determination of oil content of the seed. The bulk of oil used in this research work was obtained by solvent extraction. $3 \mathrm{~kg}$ of the dried, ground seed was introduced into a plastic container containing 3 liters of n-hexane. The mixed content of the container were vigorously shaken after covering the container. The container was made air tight to prevent evaporation of the methanol and then kept for a day for maceration of the ground seed. Then the dissolved oil in hexane was decanted and the slurry filtered. The filtrate was then distilled to recover the methanol at $650 \mathrm{C}[13]$. The percentage oil yield was calculated as:

$\%$ oil yield $=$ wejght of oil obtaind $\div$ weight of seed sample $x 100$

\subsection{Effect of process parameters on biodiesel yield}

The effects of process parameter on biodiesel yield from rubber seed oil were investigated based on one factor at a time method, involving keeping a factor constant at a time and varying the others in turn. The four factors investigate are, molar ratio of methanol to oil, catalyst concentration, reaction time and reaction temperature.

\subsection{Synthesis of RSOFAME}

Synthesis of biodiesel from the oil involves two steps, esterification by pretreatment of the oil using methanol and acid catalyst and then synthesis of the biodiesel by transesterification using methanol and sodium hydroxide catalyst.

\subsubsection{Esterification by Pretreatment of the RSO}

A pre-treatment procedure was followed to reduce the excess free fatty acid of the rubber seed oil below $1 \%$. The oil sample was first heated on a heating mantle at $110^{\circ} \mathrm{C}$ for 10 minutes for any available moisture to be driven off. The sample was cooled to $60^{\circ} \mathrm{C}$ in a water bath, and then weighed into $500 \mathrm{ml}$ three necked round bottomed flask. Then methanol of $60 \% \mathrm{w} / \mathrm{w}$ of oil mixed with concentrated sulphuric acid of $7 \% \mathrm{w} / \mathrm{w}$ of oil was added. A reflux condenser was fitted into the middle arm of the flask and water circulated at the outer jacket of the condenser. A thermometer was inserted into the sample in the flask from one of the side arms. The whole setup was placed on a magnetic heating mantle and heated at $600 \mathrm{C}$ for 60 minutes at an agitation speed of $450 \mathrm{rpm}$. The mixture was then transferred into $500 \mathrm{ml}$ separating funnel where it later separated into three layers comprising water at the bottom, pre-treated oil in the middle and methanol at the upper layer. The various components were carefully tapped off, water first, the oil and finally methanol. Hot distilled water was poured into the oil in a separating funnel, shaken and allowed to stand when it separated into water and oil layers below and above in the funnel respectively. The water layer was tapped off from the separating funnel and the pretreated oil was poured into $250 \mathrm{ml}$ beakers and dried carefully in an oven regulated at a temperature of $1050 \mathrm{C}$ until the residual water evaporated completely. After this process, the pre-treated oil was made ready for transesterification [14].

\subsubsection{Production of biodiesel by transesterification}

The rubber seed oil was transesterified using methanol and sodium hydroxide catalyst. A $500 \mathrm{ml}$ three-necked round bottomed flask fitted with a condenser on the middle arm, a thermometer and sample outlet on the side arms respectively served as the reactor. The heating system consists of an electromagnetic hot plate which heats the reactor and rotates the metal knob in the reactor through an electromagnetic field. Specified quantity of the oil sample was introduced into the flask and the flask content heated to the temperature established for the reaction. Then methanol and the sodium hydroxide catalyst mixture was added in the amount established for the reaction. The stirrer was switched on at a specified speed, taking this moment as zero time of the reaction. The reaction mixture was vigorously stirred and refluxed for the required reaction 
time. At the end of methanolysis, the transesterfied product was made to stand for a day in a separating funnels where it separates into the upper biodiesel layer and the lower glycerol layer. The lower glycerol layer was tapped off first followed by the upper biodiesel layer.After transesterification, the upper ester layer may contain traces of methanol and glycerol. The remaining un-reacted sodium hydroxide and methanol might corrode the engine components, and glycerin in the biodiesel will lessen the fuel lubricity and cause injector coking and deposits [15]. Such trace of methanol is soluble in water and is therefore removed by wet washing. The methyl ester or biodiesel layer was gently washed with hot distilled water in the ratio of 3:1 water to methyl ester. The methyl ester was gently washed to prevent its loss due to formation of emulsion that results in complete phase separation [16]. The washed biodiesel was dried by heating at $1050 \mathrm{C}$ on a laboratory hot plate until all residual water was evaporated. This conforms with the findings of [17]. The percentage biodiesel yield is given by the expression of equation (1)

$\%$ biodiesel yield $=$ Volume of biodiesel produced

$$
\div \text { volume of oil used } x 100
$$

\subsection{Determination of fuel properties of RSOFAME}

The fuel properties of the rubber seed oil biodiesel were characterized based on ASTM standards. The properties determined include density, viscosity, iodine value, cetane number, acid value, free fatty acid, calorific value, flash point etc.

\section{RESULTS AND DISCUSSION 3.1 Extraction of rubber seed oil}

The rubber seeds oil was extracted with n-hexane solvent, the choice of which was based on a comparative study by [18] who obtained highest oil yield from rubber seeds using n-hexane solvent compared with other notable solvents for extraction. The result from the extraction process showed rubber seed to contain $39.8 \%$.

\subsection{The physiochemical properties of rubber seed oil}

The physicochemical properties of the extracted rubber seed oil are as summarized in Table 1.The acid value of the oil is high, $28.72 \mathrm{mgKOH} / \mathrm{g}$. High acid value is undesirable for a feed stock for biodiesel synthesis as it tend to react with excess alkali to yield soap which retards the separation of the biodiesel from the glycerol [19] and thereby reduce the amount of biodiesel produced. The saponification value of the oil $185.66 \mathrm{mgKOH} / \mathrm{g}$ is not sufficiently high to be suitable for soap production and therefore probably a good choice for biodiesel production. Iodine value shows the degree of un-saturation of the oil. The iodine value obtained $120 \mathrm{mgI} 2 / 100 \mathrm{~g}$, shows the oil to be semidrying type. Peroxide value which indicate the degree of saturation and the rancidity of the oil was obtained as $14.62 \mathrm{meq} / \mathrm{kg}$ in this work. The value of the peroxide value is high indicative of the susceptibility of the oil to peroxidation during storage and handling [20]. The kinematic viscosity and density of the oil were found to be $60.08 \mathrm{~mm} 2 / \mathrm{s}$ and $920 \mathrm{~kg} / \mathrm{m} 3$ respectively. The high density and kinematic viscosity of the oil will make its atomization in internal combustion engine difficult as this has been associated with increase in engine deposits [21] and hence cannot be used directly as biodiesel. The flash point of rubber seed oil, 1320C is moderately high. . Oils of high flash point are safe for handling and storage.

Table 1: Physiochemical properties of RSO

\begin{tabular}{|l|l|l|}
\hline Properties & Unit & RSO \\
\hline Acid value & $\mathrm{mgKOH} / \mathrm{g}$ & 28.72 \\
\hline Free fatty acid & $\%$ & 14.36 \\
\hline Saponification value & $\mathrm{mgKOH} / \mathrm{g}$ & 185.66 \\
\hline Iodine value & (gI2/100g oil) & 120.4 \\
\hline Peroxide value & $\mathrm{meq} / \mathrm{kg}$ & 14.62 \\
\hline Kinematic viscosity & $\mathrm{mm} 2 \mathrm{~s}-1$ @ 400C & 60.08 \\
\hline Fire point & $0 \mathrm{C}$ & 180 \\
\hline Flash point & OC & 132 \\
\hline Cloud point & $0 \mathrm{C}$ & 6 \\
\hline Pour point & $0 \mathrm{C}$ & 2 \\
\hline Refractive index & & 1.428 \\
\hline Specific gravity & & 0.92 \\
\hline Moisture content & $\%$ & 7 \\
\hline Density & $\mathrm{Kg} / \mathrm{m} 3$ & 920 \\
\hline
\end{tabular}


Two Step Homogeneous Catalized Metanolysis of Rubber Seed Oil To Biodiesel

\subsection{Fatty Acid Profile of RSO}

The results of the gas chromatographic analysis of the fatty acid composition of the rubber seed oil is shown in Table 2. The individual peaks of the gas chromatogram are as identified in figure 1. From the figure, the seven peaks that represent the major fatty acids present in the rubber seed oil can be identified.
For rubber seed oil, the following fatty acids were identified, $19.6 \%$ oleic acid $\mathrm{C} 18: 1,3.98 \%$ lauric acid $\mathrm{C} 12,7.75 \%$ myristic cid C14, 16.69\% palmitic acid C16, 29.058\% Stearic acid C18 which is the most abundant saturated fatty acid in the oil, $22.5 \%$ linoleic Acid $\mathrm{C} 18$, which is the most abundant unsaturated fatty acid present in the oil.

Table 2: Fatty acid profile of ubber seed oil

\begin{tabular}{|l|l|l|l|}
\hline $\begin{array}{l}\text { Components } \\
\text { Common Name }\end{array}$ & Systematic Name & Structural Formula & Concentration (\%) \\
\hline Oleic Acid C18:1 & Cis-9- & $\mathrm{C} 9 \mathrm{H} 18=\mathrm{C} 8 \mathrm{H} 15 \mathrm{COOH}$ & 19.6 \\
\hline Lauric Acid C12 & Octadecanoic & $\mathrm{CH} 3(\mathrm{CH} 2) 10 \mathrm{COOH}$ & 3.983 \\
\hline Myristic Acid C14 & Dodecanoic & $\mathrm{CH} 3(\mathrm{CH} 2) 12 \mathrm{COOH}$ & 7.750 \\
\hline Palmitic Acid C16 & Tetradecanoic & $\mathrm{CH} 3(\mathrm{CH} 2) 14 \mathrm{COOH}$ & 16.698 \\
\hline Stearic acid C18 & Hexadecanoic acid & $\mathrm{CH} 3(\mathrm{CH} 2) 16 \mathrm{COOH}$ & 29.058 \\
\hline linoleic Acid C18:2 & $\begin{array}{l}\text { Octadecanoic Octadeca- } \\
9,12-\text { Dienoic }\end{array}$ & $\mathrm{C} 6 \mathrm{H} 12=\mathrm{C} 3 \mathrm{H} 4=\mathrm{C} 7 \mathrm{H} 14 \mathrm{COOH}$ & 22.588 \\
\hline
\end{tabular}

\subsection{FTIR Analysis of Oil Samples}

The Fourier Transform Infrared Spectroscopy (FTIR) is an important analysis technique which detects various characteristic functional group present in the oil. The FTIR plot for rubber seed oil is shown in figure 2 . The various vibrations and functional groups are presented in Table 3.. For the rubber seed oil, the presence of alcohol was detected at 3412.79, 3159.938, and 2760.742 with $\mathrm{O}-\mathrm{H}$ stretching. $\mathrm{O}-\mathrm{H}$ and $\mathrm{C}-\mathrm{H}$ bending vibrations at 1380.638 and 1853.89 depicts the presence of phenol and aromatic compounds. Alkenes presence was detected at 1637.147 with $\mathrm{C}=\mathrm{C}$ vibration.

Table 3: FTIR Functional Group Frequencies of Rubber seed oil

\begin{tabular}{|l|l|l|}
\hline Frequency wave number $(\mathbf{c m}-\mathbf{1})$ & Types of Vibration & Functional Group \\
\hline $\mathbf{7 8 0 . 7 5 2 4}$ & C-H bending & \\
\hline $\mathbf{1 2 5 2 . 7 6}$ & C-O stretching & alkyl aryl ether \\
\hline $\mathbf{1 3 8 0 . 6 3 8}$ & O-H bending & Phenol \\
\hline $\mathbf{1 6 3 7 . 1 4 7}$ & C=C stretching & Alkene \\
\hline $\mathbf{1 8 5 3 . 8 9}$ & C-H bending & Aromatic compound \\
\hline $\mathbf{2 1 7 3 . 6 2 4}$ & S-C=N stretching & Thiocyanate \\
\hline $\mathbf{2 5 4 6 . 3 5}$ & S-H stretching & Thiol \\
\hline $\mathbf{2 7 6 0 . 7 4 2}$ & O-H stretching & Alcohol \\
\hline $\mathbf{3 0 1 2 . 6 2 5}$ & C-H stretching & Alkene \\
\hline $\mathbf{3 1 5 9 . 9 3 8}$ & O-H stretching & Alcohol \\
\hline $\mathbf{3 3 2 6 . 3 4 7}$ & N-H stretching & Secondary amine \\
\hline $\mathbf{3 4 1 2 . 7 9}$ & O-H stretching & Alcohol \\
\hline
\end{tabular}

\subsection{Effect of process parameters on the yield of biodiesel}

3.5.1 Effect of methanol to oil ratio on biodiesel yield
The effect of methanol to oil ratio on the yield of biodiesel is represented on Figure 3.The biodiesel yield as a function of methanol to oil molar ratio was studied between the ranges of $2: 1$, to $12: 1$. RSO biodiesel yield increased with increase in methanol to oil molar ratio up to $8: 1$. Further increase in 
methanol to oil molar ratio was not favorable to biodiesel production. This trend can be explained by the fact that increase in methanol to oil molar ratio favours transesterification reaction, but very high methanol to oil molar ratio decreases the catalytic activity of catalyst resulting in the reduction of biodiesel produced. Though the molar ratio of methanol to oil is 3:1, however to drive transesterification near to completion excess alcohol is needed but not in such excess that is detrimental to the reaction. Researchers [22,23] have reported that when too much of alcohol is used in transesterification, the polarity of reaction mixture is increased, thus increasing the solubility of glycerol and promote the reverse reaction between glycerol and biodiesel, thereby reducing biodiesel yield.

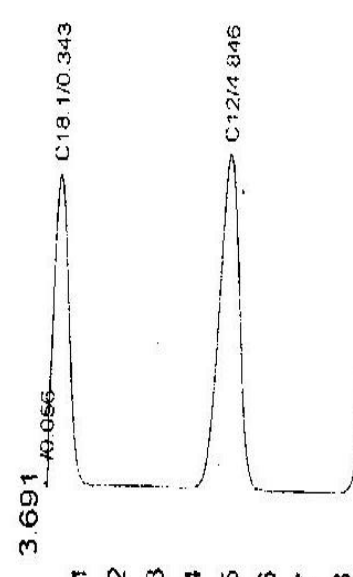

$r m+i n k \infty$
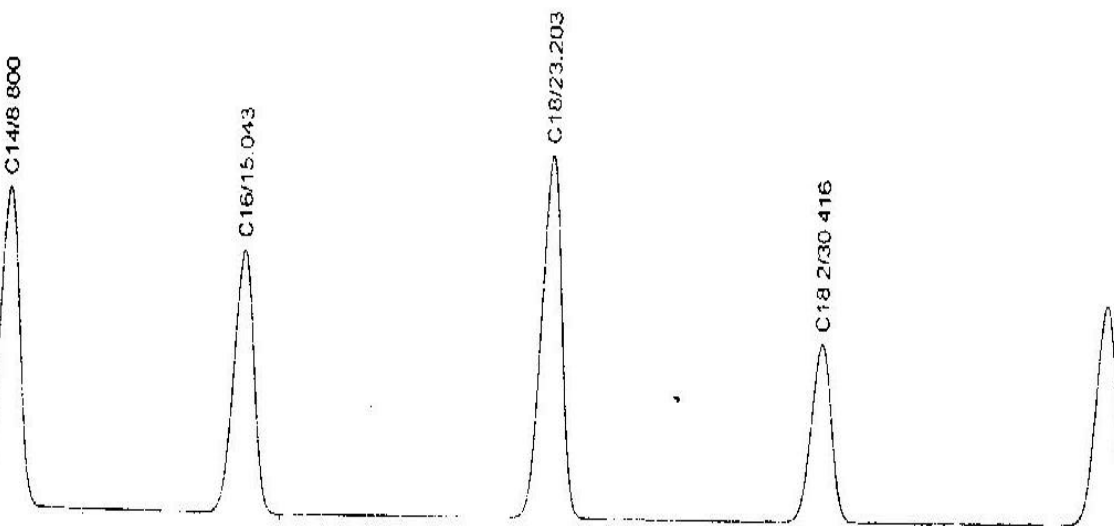

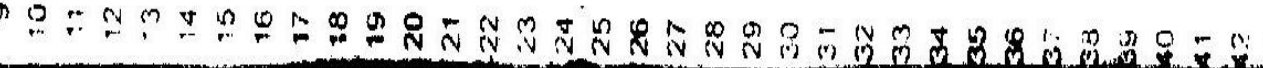

Figure 1: GC-MS spectra of RSO

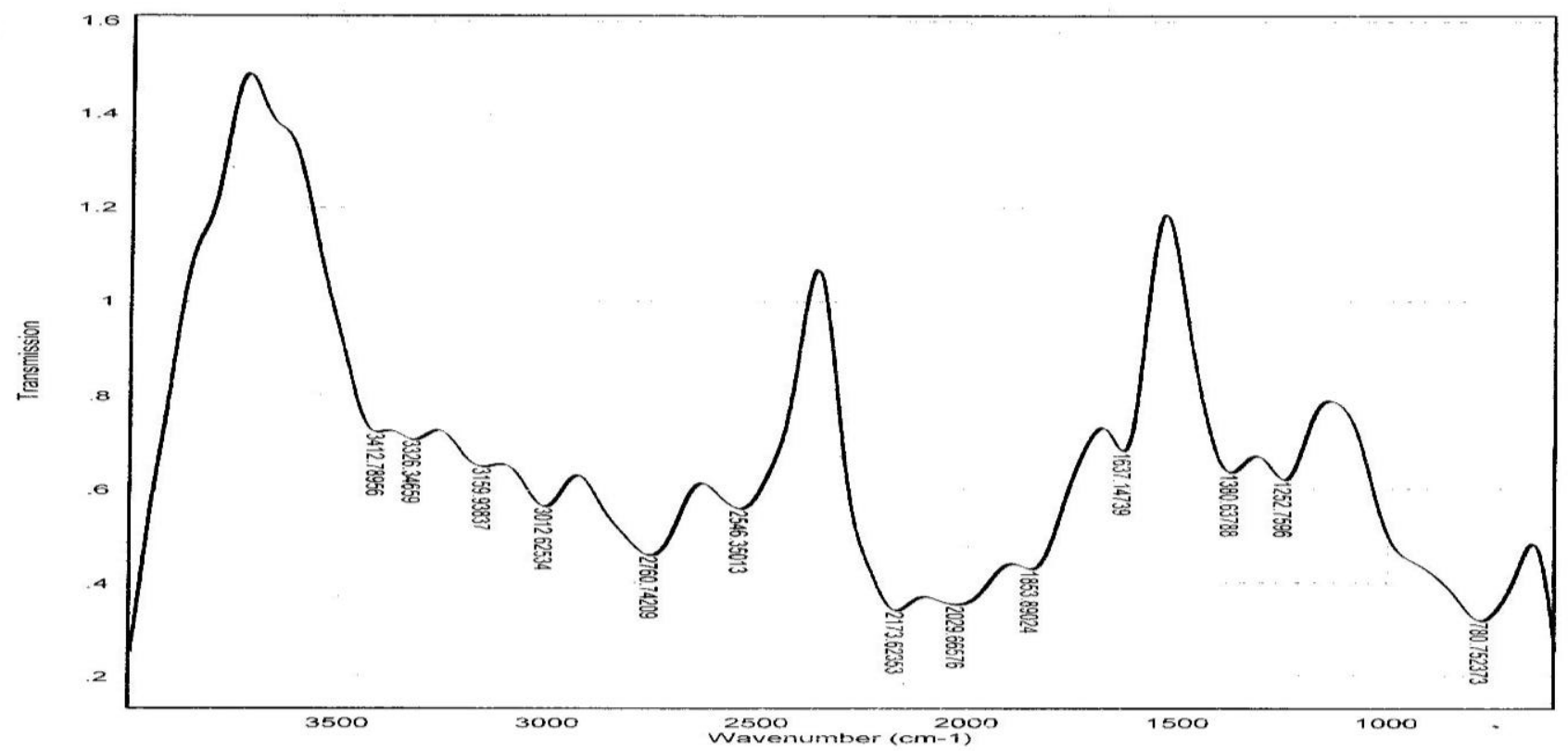

Figure 2: FTIR spectra of RSO 


\subsubsection{Effect of reaction temperature on biodiesel} yield

In order to investigate the effect of reaction temperature on rubber seed oil, the temperature was varied from $500 \mathrm{C}$ to $750 \mathrm{C}$ while the other parameters, catalyst concentration, methanol to oil molar ratio and reaction time were kept constant as shown in figure 4.The figure shows that biodiesel yield increases with increase in temperature until a maximum yield was obtained at $650 \mathrm{C}$ when the yield starts decreasing. The decrease in biodiesel yield beyond the optimum temperature of $650 \mathrm{C}$ results because below the boiling point of methanol (650C) production of biodiesel is favored but beyond the optimum temperature of $650 \mathrm{C}$ most of the methanol is lost by evaporation, leaving a reaction mixture with higher concentration of alkali catalyst that favor soap formation [24]. The formation of soap retards proper dispersion and mixing of the reaction mixture and hinders separation of glycerol from biodiesel and thus reduced the ester yield. This trend conforms with the findings of [8]..

\subsubsection{Effect of catalyst Concentration on biodiesel yield}

The effect of catalyst concentration was studied between 0.25 $1.5 \%$ (based on weight of oil) while other variables were kept constant as shown in figure 5. In a typical chemical reaction, the reactants bond must first be broken before the reaction would commence. Breaking bonds require energy and the minimum energy required to start a reaction is referred to as Activation
Energy. Catalyst tends to provide alternative reaction pathways for breaking and remaking of bonds. It could be observed from Figure 5 that as catalyst concentration increases, the biodiesel yield also increased. However, at an optimum catalyst concentration of $1 \%$ wt. the biodiesel yield peaked. Further increase in catalyst concentration beyond $1 \mathrm{wt} \%$ resulted to decrease of biodiesel yield. Decrease in biodiesel yield beyond the $1 \%$ wt. catalyst concentration can be explained by the fact that in the presence of excess catalyst above the optimum $1 \%$ wt., the excess catalyst react with the oil to form soap which increases the viscosity of the reaction mixture, hindering effective dispersion and mixing of the reactants and also hinder the separation of glycerol from biodiesel which gives rise to reduction of biodiesel produced. This is in conformity with the findings of [25] and [26].

\subsubsection{Effect of reaction time on biodiesel yield}

The effects of reaction time from 15 to 90 minutes on the yield of biodiesel from rubber seed oil was investigated. It was found that reaction time of 60 minutes was needed for a maximum yield of RSOFAME investigated and beyond it the yield decreased as shown in Figure 6. The decreased in the yield after 60 minutes may be due to reversible reaction nature of transesterification resulting in loss of esters [27]. Also longer reaction time most times allows the fatty acids present to react with alkali and this results to soap formation. The presence of soap retards the formation of ester [15].

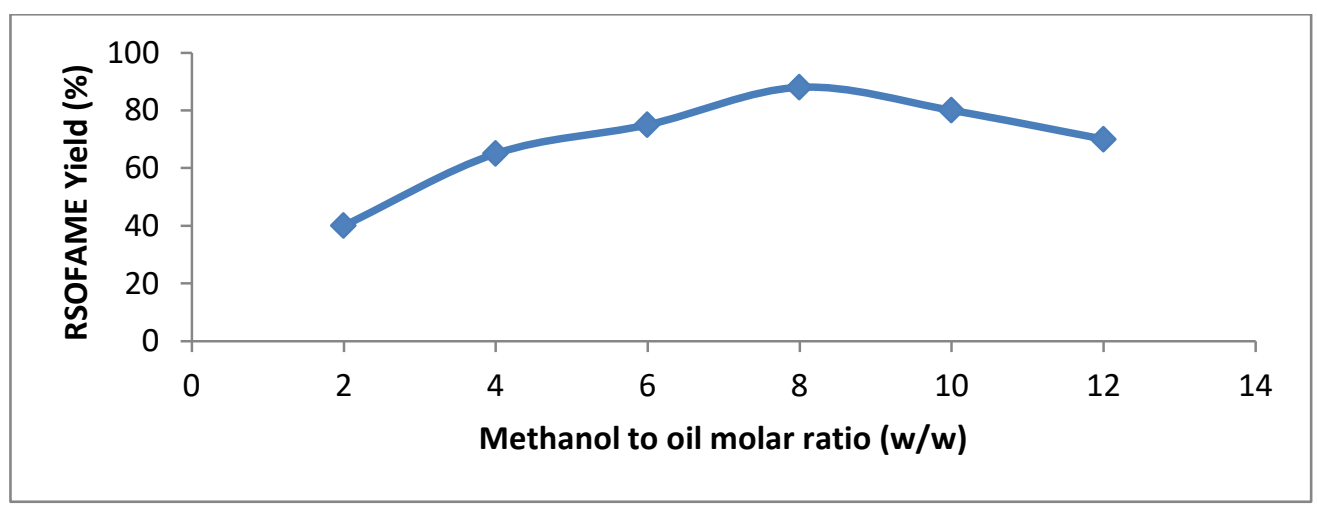

Figure 3: Effect of methanol to oil molar ratio on RSOFAME yield

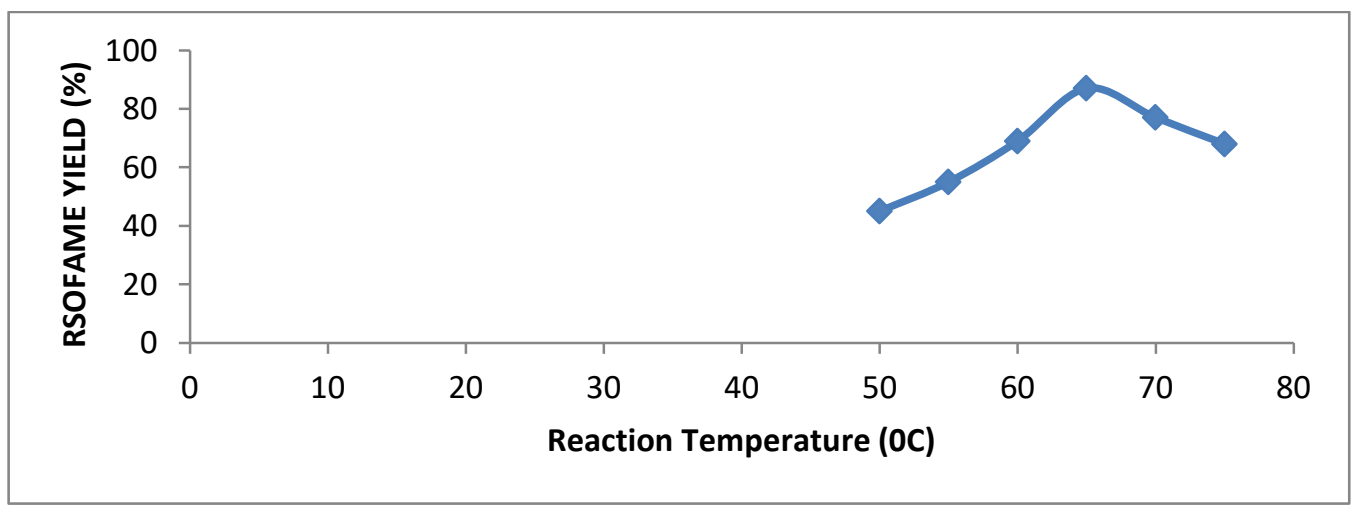

Figure 4: Effect of reaction temperature on RSOFAME yield 


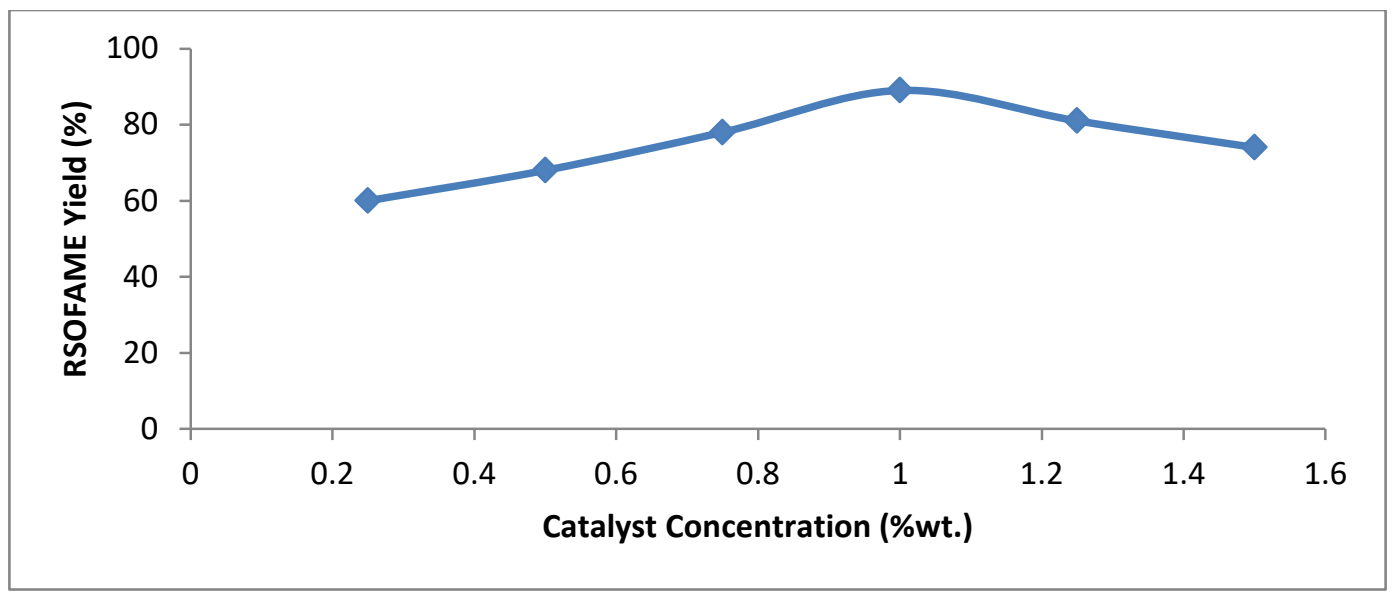

Figure 5: Effect of catalyst concentration on RSOFAME yield

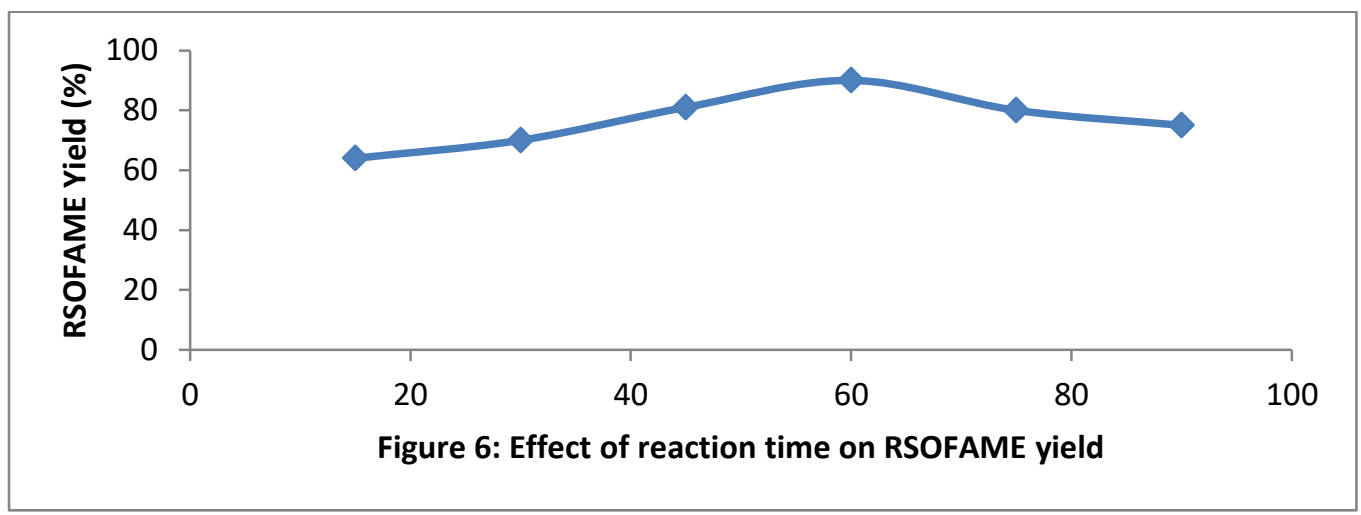

Figure 6: Effect of reaction time on RSOFAME yield

\subsection{Fuel properties of the RSOFAME produced}

The physicochemical characteristic of the produced RSOFAME produced are as given in table 4. The quality of any good biodiesel depends on the various properties such as its viscosity, density, cetane number, heating value, flash and fire point etc. The experimentally determined value of density and kinematic viscosity of the RSOFAME are $880 \mathrm{~kg} / \mathrm{m} 3$ and $4.25 \mathrm{~mm} 2 / \mathrm{s}$. These values are within the ASTM limits. High viscosity and density of fuel results in poor atomization in compression ignition engine which give rise to carbon deposits, plugging of fuel filter, and injector coking [28] and therefore reduction of the engine power output. This explains the necessity of transesterifying the crude oil to reduce the density and viscosity and make for enhanced combustion of the fuel in the combustion cylinder. However the viscosity of the fuel should not be so low as fuel of very low viscosity produces subtle spray which cannot properly get into the combustion cylinder and thus forming a fuel rich zone which leads to formation of sooth [29,30]. The values obtained for density and viscosity of RSOFAME shows that it has good injection and atomization performance. Cetane number indicates the ignition quality of the fuel. Biodiesel generally have higher cetane number than diesel [31]. Fuels of low cetane number show increase in emission due to incomplete combustion. The cetane number of the produced biodiesel is 58.2 which is within the ASTM standard limit and indicative of the fact that RSOFAME produced has good ignition response. Flash point indicates the degree of flammability of the material. Based on ASTM, a standard biodiesel should have flash point of $\geq 1300 \mathrm{C}$ for it to be classified as "nonflammable". The flash point of the RSOFAME $1640 \mathrm{C}$ is within the range of ASTM standard, indicative of the fact the rubber seed oil biodiesel is safe for handling and storage. Acid value indicates the degree of acidity of the biodiesel and therefore the corrosive tendency of the fuel to the machine parts. This was obtained as $0.32 \mathrm{mgKOH} / \mathrm{g}$. This is sufficiently low as not to have adverse effects on handling and on the machine parts. The cloud point and the pour point of RSOFAME was determined as 40C and $20 \mathrm{C}$ respectively. The cloud and pour point are not sufficiently low and might give rise to cold flow problems especially in the temperate and cold regions. However this problem could be averted by the addition of suitable cloud point and pour point depressants or by blending with diesel [32]. 
Table 6: Fuel properties of RSOFAME

\begin{tabular}{|l|l|l|l|l|}
\hline Properties & Unit & RSOFAME & ASTM Standards & Test method \\
\hline Density & Kgm-3 & 880 & $860-900$ & D93 \\
\hline Kinematic viscosity & $\mathrm{mm} 2 \mathrm{~s}-1$ & 4.25 & $1.9-6.0$ & D445 \\
\hline Cetane number & & 58.2 & $47 \mathrm{~min}$. & D613 \\
\hline Flash point & 0C & 164 & $100-170$ & D93 \\
\hline Cloud point & 0C & 4 & $-3-15$ & \\
\hline Water \&sediment & $\%$ & 0.44 & 0.5 & D2209 \\
\hline Acid value & $\mathrm{mgKOHg}-1$ & 0.32 & & D664 \\
\hline Calorific value & MJKg-1 & 38.5 & 42.06 & D35 \\
\hline Iodine value & gI2/100g oil & 72 & $42-166$ & \\
\hline Pour point & 0C & 2 & +10 Cmin & D97 \\
\hline
\end{tabular}

\subsection{Three dimensional response surface plot for FAME yield from rubber seed oil}

The 3D response surface plots of the different interaction effects were generated to estimate the effect of the combination of the independent variables on the FAME yield. Figure 6 shows the interaction effect between reaction temperature and catalyst

concentration on RSOFAMEyield. The figure shows that the biodiesel yield increases with increase in temperature and catalyst concentration. This could be as a result of the fact that more rapid reaction rate was obtained at high temperature and high catalyst concentration and thus improving biodiesel yield. However at a higher temperature and catalyst concentration in excess of the optimum (650C and $1 \% \mathrm{Wt}$.), resulted in the decrease of biodiesel yield, ostensibly as result of loss of methanol by evaporation and formation of soap by the excess alkali. Figure 7 depicts the interaction effect between methanol to oil molar ratio and reaction temperature on RSOFAME yield. The figure reveals that the biodiesel yield increases with increase in reaction temperature and methanol to oil molar ratio. However at higher values above the optimum of the reaction conditions, biodiesel yield decreased. This results because such excess methanol deactivates the catalyst while the excess temperature results to loss of methanol, all giving rise to reduced biodiesel production. Figure 8 shows that the amount of RSOFAME produced increases with increase in methanol to oil molar ratio and the catalyst concentration. However at higher methanol to oil molar ration and catalyst concentration in excess of the optimum, the yield of FAME decreased. This is because excess methanol deactivates the catalyst while excess catalyst react with the triglyceride to form soap, all resulting in the reduction of RSOFAME yield.

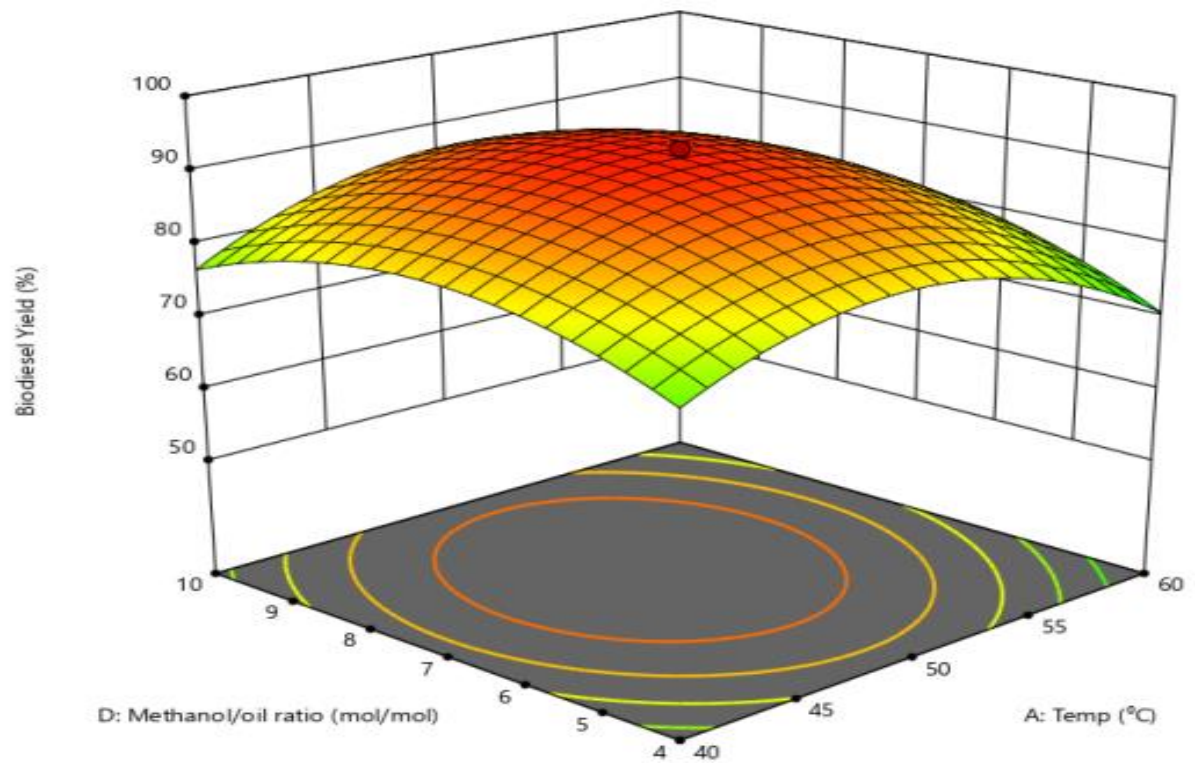

Figure 7: 3D Response surface plots showing the interaction between methanol to oil molar ratio and reaction temperature on RSOFAME yield 


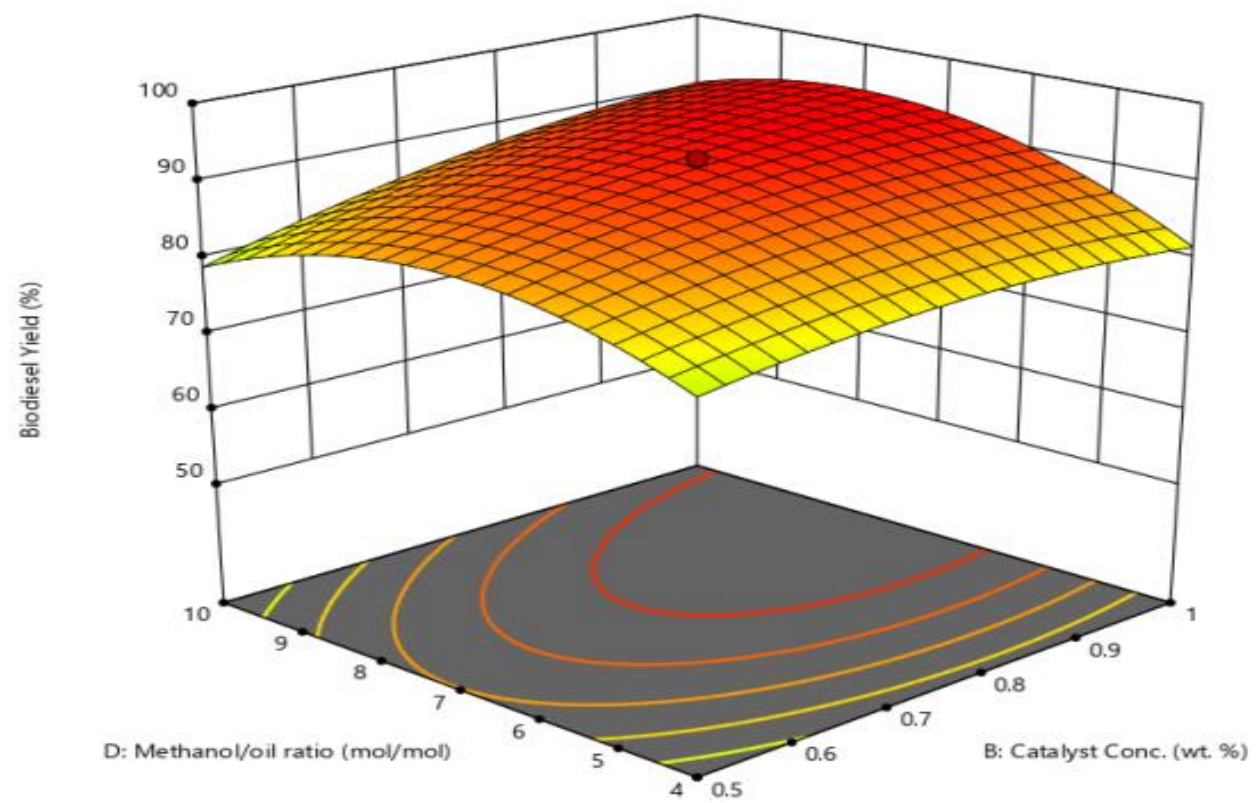

Figure 8: 3D Response surface plot showing the interaction between methanol to oil molar ratio and catalyst concentration on RSOFAME yield

\section{CONCLUSION}

The production of biodiesel from rubber seed oil by homogeneous catalysis involve two steps. First, reduction of the oil free fatty acid below $1 \%$ by esterification and second transesterification of the esterified oil with methanol in the presence of alkali catalyst.. This gives relatively high percentage of biodiesel yield (90\%).Biodiesel from the RSO can also be synthesized by one step heterogeneous catalysis involving methanolysis of the oil catalyzed by solid catalyst like calcium oxide.

\section{REFERENCES}

1. Abdulakreem, A. S and Odigure, J.O. (2002). Radiative Heat Evaluation from Gas Flaring By Computer Simulation. Association for the advancement of Modeling and simulation in enterprises, Lyon France. J. 71 No $219-$ 35 .

2. Lee, S and Shah, Y. T. (2013). Biofuels and Bioenergy: Processes and Technologies. CRC Press, Taylor and Francis Group, 6000 Broken Sound Parkway NW, Suite 300 Boca Raton, FL. ISBN 978-1-4200-8955-4.

3. Fukuda, H., Kondo, A. \& Noda, H. (2001). Biodiesel fuel production by transesterification of oils, Bioscience Bioengineering Journal, 92, 405-416.

4. Gui, M., Lee, K. \& Bhatia, S. (2008). Feasibility of edible oil vs. non-edible oil vs. waste edible oil as biodiesel feedstock. Energy, 33(11): 1646-1653

5. Umeuzuegbu J.C., (2020). Synthesis and Optimization of Biodiesel from Castor Seed Oil. World Journal of Innovative Research, 8(5), 2020, pp47-60.
6. Berchmans, H.J.\& Hirata, S. (2008). Biodiesel production from crude Jatropha curcas seed oil with a high content of free fatty acids. Bioresource Technology, 99(6), 17161721.

7. Jain, S. \& Sharma, M. (2010). Kinetics of acid base catalyzed transesterification of Jatropha curcas oil. Bioresource Technology,101(20), 7701-7706.

8. Lu, H., Liu, Y., Zhou, H., Yang, Y., Chen, M. \& Liang, B. (2009). Production of biodiesel from Jatropha curcas L. oil. Computer and Chemical Engineering 33(5), 1091-1096.

9. Ragit, S.S., Mohapatra, S..K, Kundu, K. \& Gill, P. (2011). Optimization of neem Methyl ester from transesterification process and fuel characterization as a diesel substitute. Biomass Bioenergy 35(3), 1138-1144.

10. Kochhar, S.L.; "Tropical crops, text book of economic botany" Hong Kong, Machmillan; 1986.

11. Ramadhas, A.S. Muraleedharan, C. and Jayaraj.; "Performance and emission evaluation of a

diesel engine fueled with methyl esters of rubber seed oil"; Renewable Energy. 30: pp (1789-1800); 2005.

12. Gimbun, J. S. Ali, S. C. Kanwal, L. A. Shah, N. H. Ghazali, C. K. Cheng and Nurdin S.(2012) "Biodiesel Production from Rubber Seed Oil Using A Limestone Based Catalyst," Advances in Materials Physics and Chemistry, vol. 2, pp. 138-141,

13. AOAC (1990). Official Methods of Analysis, 15th edition, Association of Official Analytical Chemists. Washington DC

14. Nakatani, N., Takamori, H., Takeda, K. \&Sakugawa, H. (2009). Transesterification of soybean oil using combusted oyster shell waste as a catalyst. Bioresource Technology 100(3), 1510-1513. 
Two Step Homogeneous Catalized Metanolysis of Rubber Seed Oil To Biodiesel

15. Ogunsuyi, H.O. (2015). Production of biodiesel using African pear (Dacryodes edulis) seed oil as feedstock. Academic Journal Biotechnology 3(5), 085-092.

16. Hanumanth, M., Hebbal, O.D. \& Navindgi, M.C. (2012). Extraction of biodiesel from vegetable oil and their comparisons; International Journal of Advanced Scientific Research and Technology, 2(2), 2249-9954.

17. Akpan , U.G., Jimoh A. and Mohammed, A.D. (2006) Extraction, Characterization and Modification of Castor Seed Oil. Leonardo Journal of Science.

18. Mohd-Setapar S.H., Lee Nian-Yian and Mohd-Sharif N.S. (2014) Extraction of rubber (Hevea brasiliensis) seed oil using soxhlet method. / Malaysian Journal of Fundamental and Applied Sciences Vol.10, No 1-6

19. Berchmans, H.J.\& Hirata, S. (2008). Biodiesel production from crude Jatropha curcasL.seed oil with a high content of free fatty acids. Bioresource Technology, 99(6), 17161721.

20. Mohammed M. I. and Hamza Z. U., "Physicochemical Properties of Oil Extracts from Sesamum Indicum L. Seeds Grown in Jigawa State -Nigeria," J. Appl. Sci. Environ. Manage, vol. 12, no. 2, pp. 99 - 101, 2008.

21. Kinast JA. (2007) Production of Biodiesels from Multiple Feedstock and Properties of Biodiesels and Biodiesel/Diesel Blends Final Report 1 in a series of 6.U.S. Department of Energy

22. Marchetti, J. M., Miguel, V.U. and Errazu, A.F. (2007). Possible Methods for Biodiesel Production. Renewable and Sustainable Energy Reviews, 11, 1300 - 1311.

23. Rashid, U. and Anwar, F. (2008). Production of Biodiesel through Optimized Alkaline Catalyzed Transesterification of Rapeseed Oil. Fuel, 87, 265 - 273.

24. 24 Umeuzuegbu, J.C., Synthesis and Characterization of Biodiesel from Avacado pear oil, (2020). International Journal of Engineering, Technology and Science, 3(1), pp 14-26.

25. Enciner, J. M., Gonzalez, J.F., Rodriguez, J. J. and Tajedor, A. (2002). Biodiesels Fuel from Vegetable Oils: Transesterification of Cynara Cardunculus L. Oils with Ethanol. Energy and Fuels, 16, 443

26. Jagadale, S. S. \& Jugulkar, L. M. (2012). Review of various reaction parameters and other factors affecting on production of chicken fat based biodiesel, International Journal on Model Engineering Resource, 2(2), 407-411.

27. Zheng, S., Kates, M., Dubé, M. A. and McLean, D. D. (2006). Acid-Catalyzed Production of Biodiesel from Waste Frying Oil. Biomass and Bioenergy, 30, 267 - 272.

28. Tat, M.E.; Van Gerpan, J.H. (1999). The Kinematic Viscosity of Biodiesel and its Blends with Diesel Fuel. JAOCS. 76, 1511-1513

29. Endah, M.M.P., Rachimoellah, M., Nidya, S. \& Ferdy, P. (2012). Biodiesel production from kapok seed oil (Ceiba pentandra) through the transesterification process by using Cao as catalyst, International Research Journal, 12(2),3-7

30. Ezekwe, C. C. \& Ajiwe, V. (2014). The variations of physiochemical properties of biodiesel blends with the blend ratios. International Journal of Science Innovations and Discoveries, 4,11-14.

31. Mittelbach, M. \& Remschmidt, C. (2004). Biodiesel: Comprehensive Handbook. Graz, Austria.. Mittelbach 102120.

32. Prafulla, D. P., Veera, G. G., Harvind, K. R., Tapaswy, M. \& Shuguang, D. (2012). Biodieselproduction from waste cooking oil using sulfuric acid and microwave irradiation processes. Journal of Environmental Protection, 3, 111 117. 